\title{
Kinetic and thermodynamic study of phenol removal from water using activated carbon synthesizes from Avocado kernel seed
}

\author{
Kassahun Dejene, Khalid Siraj ${ }^{1}$, and Shimeles Addisu Kitte \\ Department of Chemistry, College of Natural Sciences, Jimma University, P O Box 378, Jimma, \\ Ethiopia \\ ${ }^{1}$ Email: chemdocprof@gmail.com
}

Keywords: Chemisorbed, monolayer, carbonization, activated carbon, adsorption

\begin{abstract}
This study was aimed for removal of phenol from water using activated carbon synthesize from avocado kernel seeds by adsorption onto it. For adsorption process cleaned and washed avocado kernel seeds (Persea americana) were dried at $100^{\circ} \mathrm{C}$ in an oven overnight and carbonization was carried out by increasing the furnace temperature at a rate of $5{ }^{\circ} \mathrm{C} / \mathrm{min}$ to a final temperature of $800{ }^{\circ} \mathrm{C}$ for 160 minutes. Then, the activated carbon was powdered and sieved, washed with distilled water until the solution $\mathrm{pH}$ reached 7.0. Optimization of activated carbon was performed through effects of solution $\mathrm{pH}$, contact time; initial phenol concentration and temperature of the adsorption. The kinetic studies of the adsorption process were achieved by verifying various models and the data obtained was best fitted to pseudo-second-order kinetic model. The isotherms models were analyzed with Langmuir, Freundlich and Temkin to validate the adsorption process. It was found that Langmuir model was best fitted to the obtained result for both adsorbents.
\end{abstract}

\section{INTRODUCTION}

Common organic pollutants include biphenyls, phenols, pesticides, hydrocarbon, detergents, oils, greases, pharmaceuticals, proteins, and carbohydrates [1-4]. Phenols and its derivatives are widely used for the commercial production of a wide variety of resins including phenolic resins, which is an automobile manufacturing material and appliances, epoxy resins and adhesives, and polyamide for various applications [5,6]. Phenols and phenolic compounds are considered as priority pollutants since they are harmful to aquatic life including organisms especially human, at low concentrations and can be toxic when present at elevated levels and are known or suspected to be carcinogens. Phenol decomposition is difficult due to its stability and its solubility in water. It has a strong and unpleasant smell which makes the contaminated water totally unusable $[7,8]$.

Phenol being highly toxic and difficult to degrade biologically, it has led to setting up of rigid limits (phenolic compounds in industrial effluent and drinking water $1 \mathrm{ppm}, 1 \mathrm{ppb}, 0.5 \mathrm{ppm}$ and $2 \mathrm{ppb}$ ) on the acceptable level of phenol in the environment [9, 10]. Chronic toxic effects due to phenolic compounds reported in humans include vomiting, difficulty in swallowing, anorexia, liver and kidney damage, headache, fainting and other mental disturbance [11]. The toxicity levels usually range between the concentrations of $10-24 \mathrm{mg} / \mathrm{L}$ for human and $9-25 \mathrm{mg} / \mathrm{L}$ for fish. Since it is harmful compound there is a necessity for its removal in order to preserve the environmental quality, thus as recent studies shown that biotic and abiotic processes can degrade phenol [12].

To mitigate these toxic organic pollutants researchers devised different conventional and advanced methods such as chemical precipitation, chemical oxidation or reduction, ion exchange, sludge separation, reverse osmosis, membrane separation, electrochemical treatment, and evaporation [13]. However, these methods face drawbacks as cost incompatibility, sludge production, removal inefficiency. Adsorption has been found to be a superior technique as compared to other methods of waste treatment in terms of cost, the simplicity of design and operation, availability, effectiveness, and their insensitivity to toxic substances $[14,15]$.

The more recent methods for the removal of organic pollutants from potable water and wastewater were compiled and reported in the form of review article [16]. So, it leads to attachment of adsorbate molecules at the specific functional group on the adsorbent surface. It is true that choice 
of adsorbent plays a very important role [17]. This technique is quite popular due to the availability of a wide range of adsorbents, which makes it an effective and attractive process for the removal of non-biodegradable pollutants (including dyes and phenolic compounds) from wastewater [18, 19]. Activated carbon due to its extended surface area, high adsorption capacity, microporous structure and special surface reactivity makes it one of the most effective adsorbents for organic compounds removal [20,21].

Hence, this study was conducted to increase the characteristics adsorption of phenolic compounds from drinking and aqueous solution using both $\mathrm{K}_{2} \mathrm{CO}_{3}$ and $\mathrm{HCl}$ as an activating agent and was also compared the adsorption capacity of activated carbons based on solution $\mathrm{pH}$, contact time, the initial concentration of adsorbate, adsorbent doses, and temperature effect.

\section{MATERIALS AND METHODS}

\subsection{Materials}

Potassium carbonate, $\mathrm{K}_{2} \mathrm{CO}_{3}$ solution (43\% by mass) and hydrochloric acid, $\mathrm{HCl}(2 \mathrm{M})$ aqueous solution used to impregnate the collected avocado kernel seeds by appropriate proportion. $0.1 \mathrm{M}$ solution of Sodium hydroxide, $\mathrm{NaOH}(\mathrm{BDH}$, England) for $\mathrm{pH}$ adjustment. Distilled water and deionized water that used to prepare a standard stock solution. $1.0 \mathrm{~g} \mathrm{C}_{6} \mathrm{H}_{5} \mathrm{OH}$ purity $>98 \%$ (sigma Aldrich) standard, that used for preparing the standard phenolic compounds for adsorption process. The instruments used for this study are UV-visible spectrophotometer (double beam model T80+). For use at 460 to determine the complex concentration during extraction of phenolic compounds from drinking water and using wavelength $272 \mathrm{~nm}$ for determination of its concentration at equilibrium and after a certain time. Electrical furnace (Model Nabertherm ${ }^{(\mathrm{R})}$ ) used for preparing activated carbon made from avocado kernel seed. Fourier transforms infrared [FT-IR] spectrophotometer (Spectrum 65 FT-IR, Perkin Elmer model) used for functional group identification of prepared activated carbon before and after adsorption.

\subsection{Preparation of Activated Carbon}

Avocado kernel seeds (persea Americana) were collected and then cut into pieces 2-3 mm size approximately. The impregnation process was performed by mixing $100 \mathrm{~g}$ of raw material with a $43 \% \mathrm{~K}_{2} \mathrm{CO}_{3}$ solution (AC-1) and hydrochloric acid $(2 \mathrm{M})$ at a ratio of $1: 2(\mathrm{~W}: \mathrm{V})$ separately (AC-2). This mixture was heated in an oven at $50^{\circ} \mathrm{C}$ for $12 \mathrm{~h}$. The raw material was then sieved, washed with distilled water until the solution $\mathrm{pH}$ was reached 7.0 and dried again at $100^{\circ} \mathrm{C}$ overnight in an oven. The sample was then placed in a vertical tubular stainless steel reactor and placed in an electric furnace for $160 \mathrm{~min}$ maintained at $800^{\circ} \mathrm{C}$ with a rate of $5^{\circ} \mathrm{C} / \mathrm{min}$. The product was cooled to room temperature, washed with distilled water, and then dried at $100^{\circ} \mathrm{C}$ in an oven for 3 hours. The product was then preserved in desiccator for further analysis.

\subsection{Adsorption Study}

Equilibrium studies were carried out by taking $0.3 \mathrm{~g}$ powdered activated Carbon with $25 \mathrm{~mL}$ phenol solution of different initial concentrations $(10,20,30,50,60$, and $70 \mu \mathrm{g} / \mathrm{L})$ for the aqueous solution of phenol in twelve $(250 \mathrm{~mL})$ conical flask. The $\mathrm{pH}$ of the solutions was adjusted to 6.0 by adding either $0.1 \mathrm{M} \mathrm{HCl}$ or $0.1 \mathrm{M} \mathrm{NaOH}$ solutions. The suspensions were agitated at $160 \mathrm{rpm}$ on a shaker at room $30{ }^{\circ} \mathrm{C}$ for $100 \mathrm{~min}$ and $120 \mathrm{~min}$ for AC-1 and AC-2 respectively. At the end of the agitation period, the samples were filtered through Whatmann № 540 filter paper and centrifuged for $5 \mathrm{~min}$ and the supernatant phenolic compound's concentrations in the filtrate was analyzed using a UV/Vis spectrophotometer measuring absorbance at the wavelength of maximum absorption of phenol $(272 \mathrm{~nm})$.

\subsubsection{Effect of Contact Time}

The effect of contact time on the amount of phenol removal was analyzed over the contact time range from 20 to $160 \mathrm{~min}$. $0.3 \mathrm{~g}$ each of activated carbon was weighed and put in twelve $(250 \mathrm{~mL})$ conical flasks. From stock solution $25 \mathrm{~mL}$ of $10 \mu \mathrm{gL}^{-1}$ concentration of phenol solution was 
prepared separately in distilled water and was added to the biomass. The $\mathrm{pH}$ values of these suspensions were adjusted to 6.0. The flasks were labeled for a time interval of 20, 40, 60, 80, 100, 120,140 and $160 \mathrm{~min}$. The flasks were tightly covered with cellophane and shaken at $160 \mathrm{rpm}$ for the appropriate time intervals on an electric shaker at $30^{\circ} \mathrm{C}$. The supernatants were analyzed using a UV-Visible spectrophotometer.

\subsubsection{Effect of $\mathbf{p H}$}

$0.3 \mathrm{~g}$ each of powdered activated carbon was weighed and introduced into twelve $(250 \mathrm{~mL})$ conical flasks. $25 \mathrm{~mL}$ of $10 \mu \mathrm{gL}^{-1}$ solutions of phenol was added separately to the activated carbon. The $\mathrm{pH}$ value of these suspensions was adjusted to 2.0, 4.0, 6.0, 8.0, 10.0 and 12.0 by adding a solution of either $0.1 \mathrm{~N} \mathrm{HCl}$ or $0.1 \mathrm{~N} \mathrm{NaOH}$. The flasks were tightly covered with cellophane and shaken for $100 \mathrm{~min}$ and $120 \mathrm{~min}$ at $160 \mathrm{rpm}$ for AC-1 and AC-2 respectively. The suspension was filtered through centrifuged and analyzed.

\subsubsection{Effect of Initial Phenol Concentration}

Equilibrium studies were carried out by contacting $0.3 \mathrm{~g}$ activated carbon with $25 \mathrm{~mL}$ phenol was prepared in distilled water from a stock solution of different initial concentrations $(10,20,30,50$, 70 and $100 \mu \mathrm{g} / \mathrm{L})$ in twelve $(250 \mathrm{ml})$ conical flask. The $\mathrm{pH}$ of the solutions was adjusted to 6.0 by adding $0.1 \mathrm{~N} \mathrm{HCl}$ or $0.1 \mathrm{~N} \mathrm{NaOH}$ solutions. The suspensions were agitated at $160 \mathrm{rpm}$ on a shaker at a temperature $\left(30^{\circ} \mathrm{C}\right)$ for $100 \mathrm{~min}$ for $\mathrm{AC}-1$ and 120 for $\mathrm{AC}-2$. At the end of the agitation period, the samples were centrifuged for $5 \mathrm{~min}$ and the supernatant phenol solution was filtered through filter paper. Phenol concentrations in the filtrate were analyzed using a UV/Vis spectrophotometer measuring absorbance at the wavelength of maximum absorption of $(272 \mathrm{~nm})$.

\subsubsection{Effect of Adsorbent Dosage}

Different masses of activated carbon ranging from $0.1,0.2,0.3,0.4,0.5$ and $0.6 \mathrm{~g}$ were accurately weighed and transferred into twelve $(250 \mathrm{~mL})$ conical flasks. $25 \mathrm{~mL}$ of phenol was added separately to each of the conical flasks. The flasks were tightly covered with cellophane and shaken for 100 min and $120 \mathrm{~min}$ at $160 \mathrm{rpm}$. At the end of the time of agitation, the suspension was filtered using Whatmann № 540 filter paper, and centrifuged for 5 minutes and the supernatant solution were analyzed by a UV-visible spectrophotometer.

\subsubsection{Effect of Temperature}

A $25 \mathrm{~mL}$ of phenol solutions was mixed separately with an initial concentration of 10,20 and $30 \mu \mathrm{g}$ $\mathrm{L}^{-1}$ was placed in eighteen $(250 \mathrm{~mL})$ conical flasks. $0.3 \mathrm{~g}$ each of activated carbon was added to these solutions. The conical flasks were labeled at temperatures of 30,35 , and $40^{\circ} \mathrm{C}$ respectively. The flasks were agitated at $160 \mathrm{rpm}$ and heated on a thermostat water bath to the appropriate temperatures for respective time for both activated carbons.

\subsection{Adsorption Isotherm}

In a solid-liquid system adsorption results in the removal solutes from solution and their accumulation at a solid surface. A dynamic equilibrium established between the solute remaining in the solution with that adsorbed on the solid phase. In this study the extent of phenolic compounds adsorption capacity at equilibrium, $q_{e}(\mu \mathrm{g} / \mathrm{g})$, was calculated by using an adsorption isotherm Eq. (1)

$$
\begin{aligned}
& q_{e}=\frac{\left(C_{o}-C_{e}\right) V}{W} \\
& q_{t}=\frac{\left(C_{o}-C_{t}\right) V}{W}
\end{aligned}
$$


The percentage of phenolic compounds removal was calculated using Eq. (3):

$$
\text { Removal }(\%)=\frac{C_{o}-C_{e}}{C_{o}} \times 100
$$

$C_{0}$ corresponds to the initial concentration of phenolic compounds, and $C_{\mathrm{e}}(\mu \mathrm{g} / \mathrm{g})$ corresponds to the concentration of phenolic compounds at equilibrium, $V(\mathrm{~L})$, volume of the solution, and $W(\mathrm{~g})$ is the mass of the dry adsorbent.

\section{RESULT AND DISCUSSION}

\subsection{Characterization of the Adsorbent}

\subsubsection{Physicochemical Characteristics of Adsorbent}

Physicochemical characteristics of avocado kernel seeds are given in Table 1. The activation process of Persea americana by adopting $43 \% \mathrm{~K}_{2} \mathrm{CO}_{3}$ and $2 \mathrm{~N} \mathrm{HCl}$ treatment leads to the corrosion of the surface of a carbonaceous material and the appearance of micro-pores, macropores, and mesopores.

Table 1: Physicochemical characteristics of Persea americana activated carbon treated by $43 \%$ $\mathrm{K}_{2} \mathrm{CO}_{3}(\mathrm{AC}-1)$ and $2 \mathrm{~N} \mathrm{HCl}(\mathrm{AC}-2)$

\begin{tabular}{lcc}
\hline \multirow{2}{*}{ Parameters } & \multicolumn{2}{c}{ Types of activated carbon } \\
& AC-1 & AC-2 \\
\hline $\mathrm{pH}$ & 6.86 & 6.86 \\
Moisture content $(\%)$ & 19.56 & 11.75 \\
Volatile content $(\%)$ & 3.912 & 5.0 \\
Ash content $(\%)$ & 30.44 & 4.97 \\
Mesh size $(\mu \mathrm{m})$ & 150 & 150 \\
Fixed carbon $(\%)$ & 46.08 & 78.28 \\
Organic carbon content $(\%)$ & 16.91 & 2.76 \\
\hline
\end{tabular}

\subsubsection{FT-IR Analysis}

FT-IR spectrum is an essential tool to identify the surface functional groups which contribute significantly to enhance adsorption efficiency of activated carbon by surface complexation. The functional groups on the avocado kernel seed activated carbons (raw, untreated, AC-1 and AC-2) are closely identical to one another. FTIR spectra shown in Figure 1, display a number of peaks and indicated a complex nature of the adsorbent [22]. Bands at $3326-3389 \mathrm{~cm}^{-1}$ were assigned to O-H stretch of the phenol functional group [23]. The absorption bands observed in this area particularly correspond to the vibration of hydroxyls fixed on the surface of carbon and water chemisorbed on carbon and the presence of N-H bond of an amino group of avocado kernel seeds [24]. 2924 to $2818 \mathrm{~cm}^{-1}$ correspond to stretching $\mathrm{C}-\mathrm{H}$ groups, and they represent aliphatic hydrocarbons. The bands that were observed at 1458 to 1443 was due to aromatic $\mathrm{C}=\mathrm{C}$ stretch vibration and the bands that have been observed at 1368 to 1353 due to alcoholic $\mathrm{C}-\mathrm{O}-\mathrm{H}$ bending coupled with $\mathrm{C}-\mathrm{C}$ stretch vibration [8] and finally the band that was observed at 1093 to $1021 \mathrm{~cm}^{-1}$ due the presence of $\mathrm{C}-\mathrm{O}$ stretching. From Figure 1 we observed that the O-H stretching vibration onto both AC-1 and AC-2 before and after loaded was affected due to adsorption of phenolic compounds takes place on the surface of activated carbon and C-O bending vibration was changed on both activated carbon of loaded and unloaded activated carbons. Intensity changes of both activated carbons on the $\mathrm{O}-\mathrm{H}$ and $\mathrm{C}-\mathrm{O}$ vibrations was due to the interaction of $\mathrm{H}^{+}$ion with the surface of negatively charged activated carbon in acidic $\mathrm{pH}$, thus, the adsorption of phenolic compounds increase up to $\mathrm{pH}$ 6. On the other hand, the presence of $\mathrm{C}=\mathrm{C}$ of aromatic stretching and $\mathrm{C}-\mathrm{H}$ stretching of alkanes mentioned spectra on figure $1(\mathrm{a}, \mathrm{b})$ are not highly affected by the adsorption of phenol on both activated carbon. Finally, the spectra of raw avocado kernel seeds, untreated and unloaded activated carbons have 
almost the same. This indicates that the adsorption of phenolic compounds on this carbon materials is lower due to change of functional group intensity during adsorption is very small.

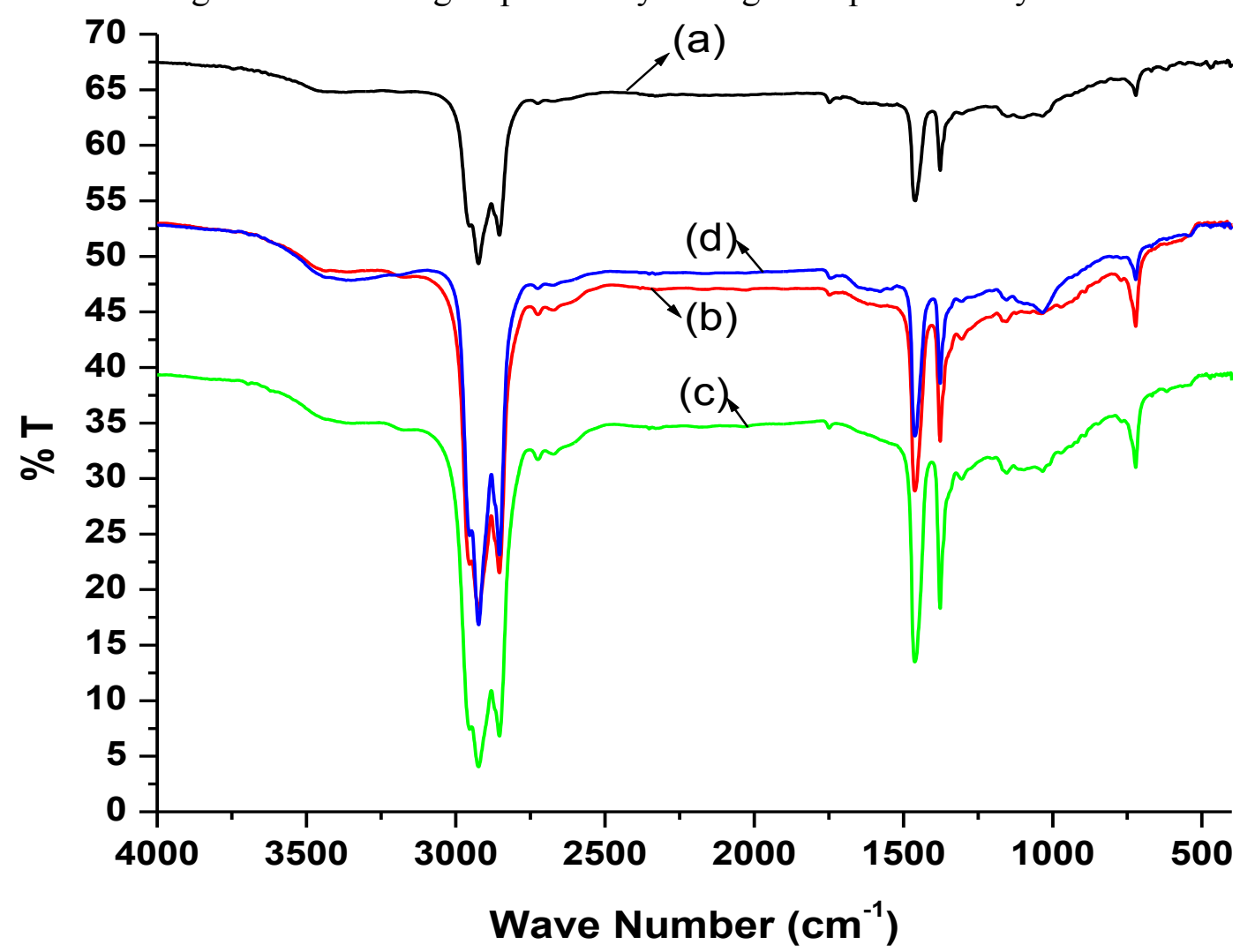

Figure 1: IR spectrum represents (a) unloaded AC-1; (b) Loaded AC-1; (c) unloaded AC-2;

(d) Loaded AC-2

\subsection{Optimization of Parameters}

\subsubsection{Effect of Contact Time and initial concentration}

Figure 2 presents the plot of phenolic compounds removal versus contact time for AC-1 \& AC-2 at initial concentrations between 10 and $100 \mu \mathrm{g} / \mathrm{L}$ at $30^{\circ} \mathrm{C}$ with a contact time of between 20 and 160 min. The increase in contact time increased the percentage removal of phenolic compounds in both activated carbons. Rapid removal was noticed initially and reached equilibrium at around $100 \mathrm{~min}$ and $120 \mathrm{~min}$ for AC-1 and AC-2 respectively. The initial rapid phase is due to the availability of more adsorption sites initially; as a result, there exists an increased concentration gradient between adsorbate in solution and in the adsorbent. This can be explained by strong attractive forces between phenol molecules and the sorbent and fast diffusion into the interparticle matrix to attain rapid equilibrium [25]. Phenolic compound removals versus contact time curves are single and continuous leading to saturation, suggesting the possibility of monolayer coverage of phenolic compounds on the outer surface of the adsorbent. Moreover, a number of phenolic compounds adsorbed (micrograms per grams) increased with increase in contact time. The increase in adsorption capacity with increasing phenol derivative concentration could be due to higher probability of collision between phenol molecules and adsorbent surface [26]. On the other hand, the smaller concentration of phenolic compounds onto both activated carbons gave higher percentage adsorption. 

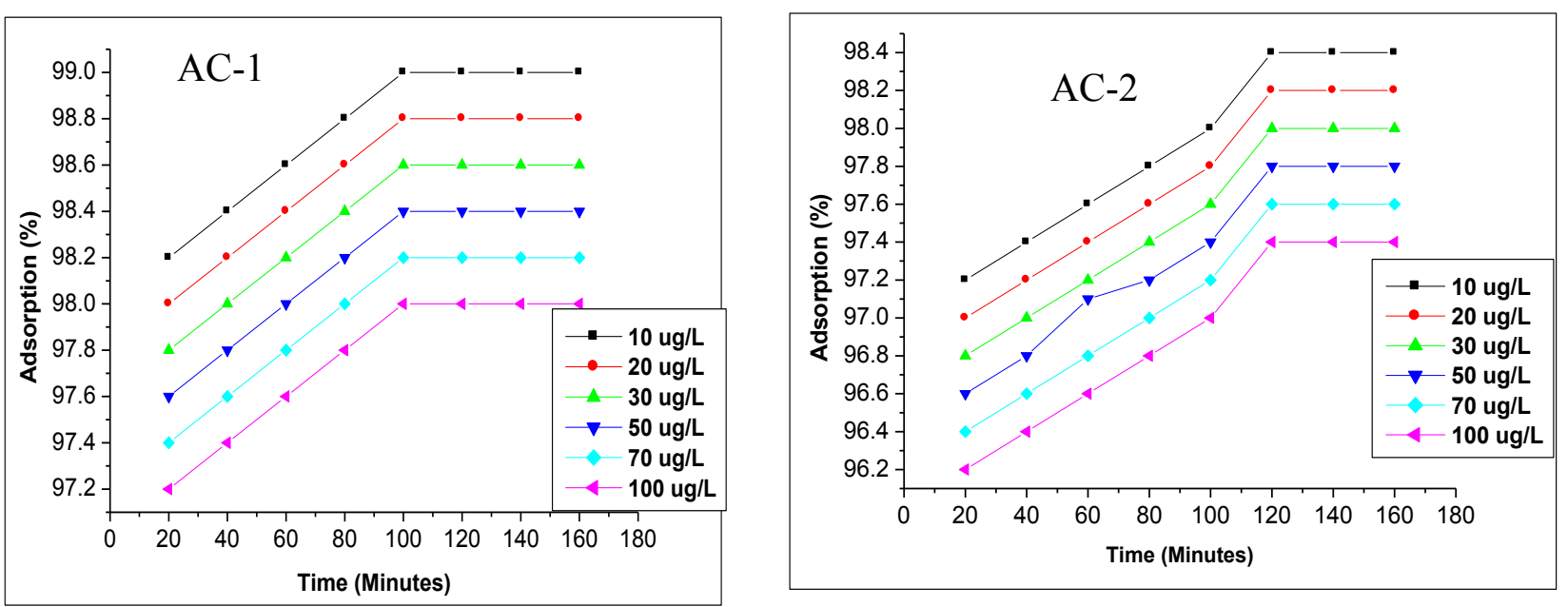

Figure 2: Effect of Initial concentration on contact time for the Adsorption of phenolic compounds at $\mathrm{pH}=6$, the mass of adsorbent $=0.3 \mathrm{~g}$, temperature $303 \mathrm{~K}$; (a) $\mathrm{AC}-1$ and (b) $\mathrm{AC}-2$.

\subsubsection{Effect of pH on Phenolic Compound Adsorption}

In adsorption process, electrostatic attraction exists between phenolate ions $\left(\mathrm{C}_{6} \mathrm{H}_{5} \mathrm{O}^{-}\right)$and adsorbent surface plays a very significant role, the oxygen of the surface carbonyl group acts as the electron donor and the phenol aromatic ring as the acceptor. Both aspects are determined by the solution $\mathrm{pH}$. Due to the amphoteric character of a carbon surface, its adsorption properties may be influenced by the $\mathrm{pH}$ value of the solution [27]. The effect of initial $\mathrm{pH}$ on the adsorption of phenol was also evaluated at $30^{\circ} \mathrm{C}$, initial concentrations of $10 \mu \mathrm{g} / \mathrm{L}$ for phenol, $100 \mathrm{~min}$. for $\mathrm{AC}-1$ and 120 minutes for AC-2 of contact time, $0.3 \mathrm{~g}$ adsorbent dose at different initial $\mathrm{pH}$ values in the range of 2-12 for solution adjusted by adding either $0.1 \mathrm{M} \mathrm{HCl}$ or $0.1 \mathrm{M} \mathrm{NaOH}$. The variation of adsorption with different values of $\mathrm{pH}$ is shown in Figure 3 below. Further, increase in $\mathrm{pH}$ causes again increase in phenolic compound uptake. In this study, the amount of phenol derivatives adsorbed is highest at $\mathrm{pH}=6$ followed by 8 , next to that the uptake of phenol gradually decreases. The $\mathrm{pH}$ also affects the degree of ionization of phenol in adsorption medium. In addition to this, the amount adsorbed of phenol increases at low $\mathrm{pH}$ values and decreases at high $\mathrm{pH}$ in both activated carbon cases. Since the $\mathrm{pKa}$ value of phenol at room temperature is 9.89 was expected to become negatively charged at this $\mathrm{pH}$ resulting in the adsorption-reduction due to the repulsion between the surface layer and the anionic phenolate [28]. In this study, the activated carbon prepared from avocado kernel seeds treated by $43 \% \mathrm{~K}_{2} \mathrm{CO}_{3}$ has a higher percent of adsorption $(99.63 \%)$ as compared to activated carbon treated with $2 \mathrm{~N} \mathrm{HCl}$ which has percentage adsorption of $99.62 \%$. The effect of the solution $\mathrm{pH}$ on the adsorption capacity of activated carbons AC-1 and AC-2 for phenols studied is shown in Figure 3. At acid $\mathrm{pH}$, the amount of phenols adsorbed was slightly increases from $\mathrm{pH} 2-6$ and, at a certain value of $\mathrm{pH} \mathrm{8-10,} \mathrm{there} \mathrm{is} \mathrm{a} \mathrm{constant} \mathrm{in} \mathrm{the} \mathrm{value} \mathrm{of} \mathrm{q}_{\mathrm{e}}$ which completely decreases above $\mathrm{pH} 10$. These results indicate that phenol is preferentially adsorbed on the surfaces of the activated carbons in their molecular form because at acidic $\mathrm{pH}$ values phenol is not dissociated. This variation in the surface charge density of the activated carbons affects their adsorption capacity, essentially when the phenol compounds are dissociated as now the phenolate anions are being repelled by the negative charge on the surface of the carbons [29]. However, the amount of phenol adsorbed depends also on the surface charge of the carbon. Thus, in the AC-2, the surface charge is lower than that of carbon AC-1. At $\mathrm{pH}$ values higher than 10, both the external and internal surfaces are negatively charged and the phenol is not dissociated. Therefore, the amounts adsorbed above that $\mathrm{pH}$ are very low in both activated carbon cases. 


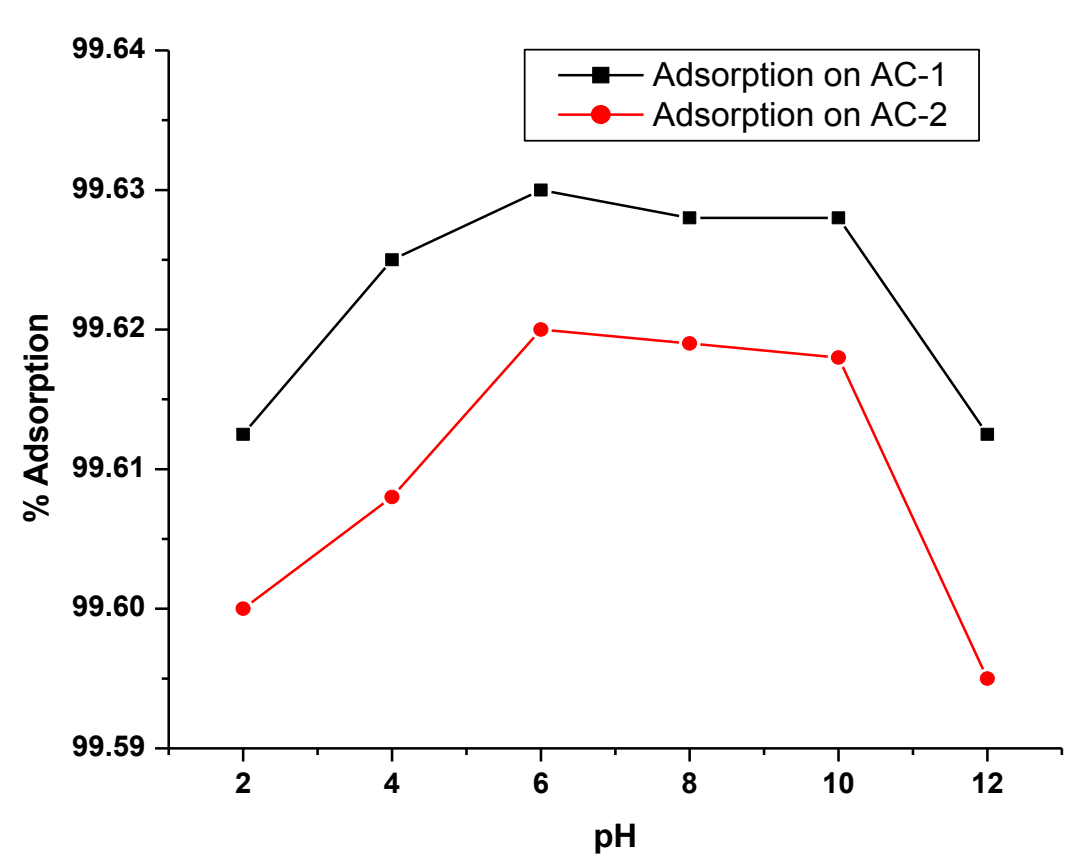

Figure 3: Effect of $\mathrm{pH}$ on the Adsorption of Phenol by Activated Carbon prepared from Avocado Kernel Seed (AC-1 and AC-2) at constant $\left(\mathrm{t}=100 \mathrm{~min}, 120 \mathrm{~min}, \mathrm{~m}=0.3 \mathrm{~g}, \mathrm{C}_{\mathrm{O}}=10 \mu \mathrm{g} / \mathrm{L}\right.$, speed $=160 \mathrm{rpm}$ and $\mathrm{T}=30^{\circ} \mathrm{C}$ )

\subsubsection{Effect of Adsorbent Dosage}

The amount of adsorbents in the water is one of the major factors which affect the adsorption capacity. The batch adsorption experiments were carried out using various amounts of AC-1 and AC-2 from 0.1 to $0.6 \mathrm{~g}$ while the $\mathrm{pH}$, agitation speed and contact time were fixed at 6-7, 160 $\mathrm{rpm}$ and 100 minutes and $120 \mathrm{~min}$, respectively. The results displayed in Figure 4 indicate that the adsorption capacity increases with increase in adsorbent dosage up to $0.3 \mathrm{~g}$, and then remains almost constant for the remaining dosages. Till $0.3 \mathrm{~g}$, the increase in percentage removal due to the greater the availability of exchangeable sites for ions. However, after certain dosage rate, which is $0.3 \mathrm{~g}$ in this study, the dosage rate was found to have no effect on the percentage removal. This indicates that the phenolic compound removal is an equilibrium reaction and is not limited by a number of adsorption sites of the adsorbent within the concentration range investigated in this study.

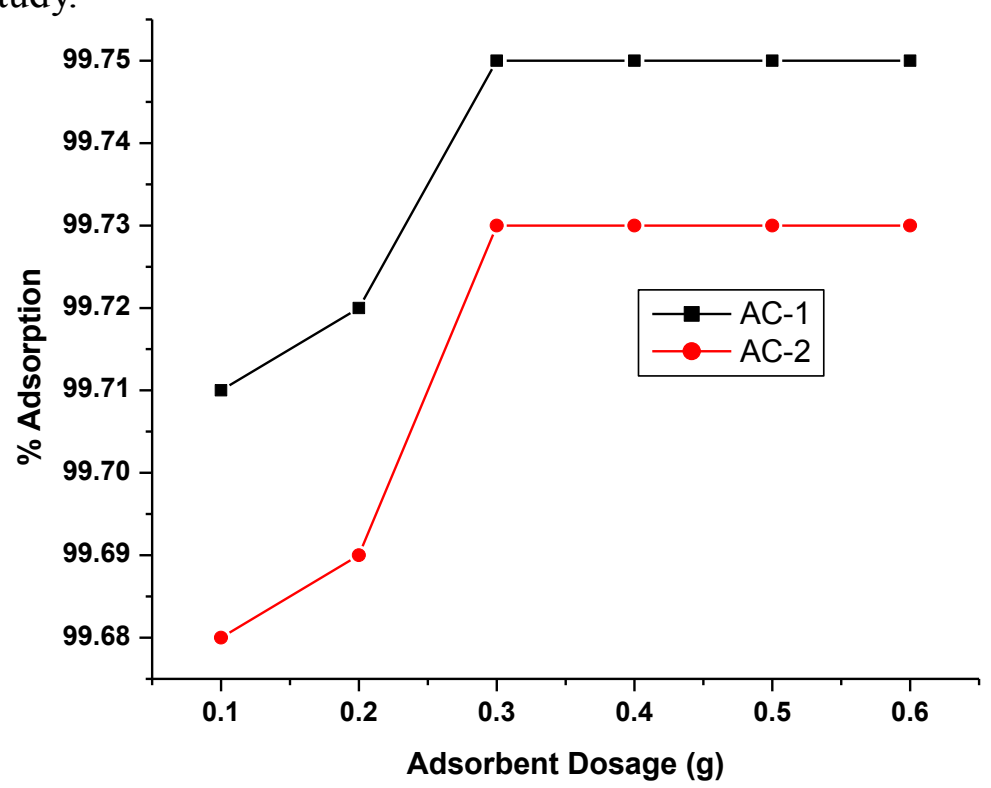

Figure 4: Effect of Adsorbent Dosages on the Percentage Adsorption of Phenol and on the Adsorption Capacity of Phenol onto Activated Carbon Prepared from Avocado Kernel Seeds (AC-1 and AC-2) 


\subsubsection{Effect of Temperature on Initial Concentration and Adsorption of Phenol}

For analyzing the effect of temperature on adsorption, phenol solutions of different concentrations namely, 10, 20, $30 \mathrm{ppb}$ were prepared. All sample solutions were maintained at $\mathrm{pH}$ of 6 and $0.3 \mathrm{~g}$ of activated carbon was added to each solution, then the samples were agitated 100 minutes for AC-1 at different temperatures 30,35 and $40^{\circ} \mathrm{C}$ respectively. It is evident as temperature increases the percentage adsorption decreases this suggesting that adsorption of phenolic compounds on activated carbon is exothermic in nature. In this study the maximum adsorption was recorded at a lower temperature $\left(30^{\circ} \mathrm{C}\right)$ and the minimum adsorption was observed at a higher temperature $\left(40^{\circ} \mathrm{C}\right)$. The increased uptake of phenol with an increase in initial concentration indicates that chemisorption more dominates over physisorption [30].

\subsection{Adsorption Isotherm}

Adsorption equilibrium provides fundamental physiochemical data for evaluating the applicability of sorption process as a unit operation. The equilibrium study has been conducted based on the commonly used adsorption isotherm models as Langmuir, Freundlich, and Temkin.

The validity and applicability of the isotherm models were confirmed by calculating the standard normal deviation (SND) and average relative error factor between the experimental data and the model estimates. The mathematical equation of SND and ARE is given below in equation 4 and 5 $[31,32]$.

$$
\begin{gathered}
N S D(\%)=100 \sqrt{\frac{1}{N-1} \sum_{i}^{n}\left[\frac{q_{i}, \exp -q i, c a l}{q_{i}, \exp }\right]^{2}} \\
A R E=\frac{100}{N} \sum_{i=1}^{n}\left|\frac{q_{i}, \exp -q_{i}, c a l}{q_{i}, \exp }\right|_{i}
\end{gathered}
$$

Where $\mathrm{q}_{\mathrm{i}}, \exp$ and $\mathrm{q}_{\mathrm{i}}, \mathrm{cal}(\mu \mathrm{g} / \mathrm{g})$ are an experimental and calculated mass of the phenolic compounds adsorbed by AC- 1 and $\mathrm{AC}-2$ at a time $\mathrm{t}$, and $\mathrm{N}$ is the number of measurements made. Smaller NSD and ARE values imply more accurate estimations.

\subsubsection{Langmuir Isotherm}

The assumption mode on the Langmuir adsorption isotherm model is that all adsorption sites have equal affinities for adsorbate molecules at one site which do not affect the adsorption of molecules at an adjacent site. The Langmuir equation was modeled using the equation 6 below and its validity was checked by regression coefficient $\left(\mathrm{R}^{2}\right)$, normal standard deviation, (NSD), average relative error (ARE) and the probability of the model with experimental data.

$$
\frac{C_{e}}{q_{e}}=\frac{1}{q_{m} b_{L}}+\frac{C_{e}}{q_{m}}
$$

Where $\mathrm{C}_{\mathrm{e}}$ is the equilibrium concentration of solute in solution $(\mu \mathrm{g} / \mathrm{L}), \mathrm{q}_{\mathrm{e}}$ is the amount of solute adsorbed at equilibrium $(\mu \mathrm{g} / \mathrm{g}), \mathrm{q}_{\mathrm{m}}(\mu \mathrm{g} / \mathrm{g})$ and $\mathrm{b}_{\mathrm{L}}(\mathrm{L} / \mathrm{mg})$ are the Langmuir constants, and $\mathrm{q}_{\mathrm{m}}$ signifies adsorption capacity and $b_{\mathrm{L}}$ is related to energy of adsorption process. A plot of Ce/qe against Ce yields a straight line and $\mathrm{q}_{\mathrm{m}}$ and $\mathrm{b}_{\mathrm{L}}$ are obtained from the slope and intercept respectively.

As can be seen from Figure 5 (a) and Table 2, Langmuir model effectively described the sorption data with all $\mathrm{R}^{2}$ values greater than 0.98 which are 0.994 and 0.985 for AC-1 and AC-2 respectively. The adsorption isotherm of phenolic compound exhibits Langmuir behavior which indicates a monolayer adsorption. The maximum monomolecular capacity is found 3.585 and 3.753 $\mu \mathrm{g} / \mathrm{g}$ phenol for both (AC-1 and AC-2) at $303 \mathrm{~K}$. According to the $\mathrm{b}_{\mathrm{L}}$ (liters per gram), parameter sorption on activated carbon is produced in the following sequence $303>308>313 \mathrm{~K}$. The essential characteristics of Langmuir isotherm can be expressed in terms of a dimensionless constant separation factor, $\mathrm{R}_{\mathrm{L}}$, which is defined as [33]: 


$$
R_{L}=\frac{1}{1+b_{L} C_{O}}
$$

Where, $b_{\mathrm{L}}$ is the Langmuir constant and $\mathrm{C}_{0}$ is the initial concentration of the adsorbate in solution. $R_{L}$ value indicates the type of isotherm to be irreversible $\left(R_{L}=0\right)$, favorable $\left(0<R_{L}<1\right)$, linear $\left(R_{L}=1\right)$, or unfavorable $\left(\mathrm{R}_{\mathrm{L}}>1\right)$. The values of $\mathrm{R}_{\mathrm{L}}$ were found to be $9.35 \times 10^{-4}, 4.678 \times 10^{-3}, 3.12 \times 10^{-3}$, $1.87 \times 10^{-4}, 1.34 \times 10^{-4}$, and $9.35804 \times 10^{-5}$ for the initial concentrations of $10,20,30,50,70$ and 100 $\mu \mathrm{g} / \mathrm{L}$, respectively, at $30^{\circ} \mathrm{C}$ for $\mathrm{AC}-1$. This indicates that adsorption of phenol is favorable on AC-1 and $\mathrm{AC}-2$ because all $\mathrm{R}_{\mathrm{L}}$ values are between 0 and 1 .
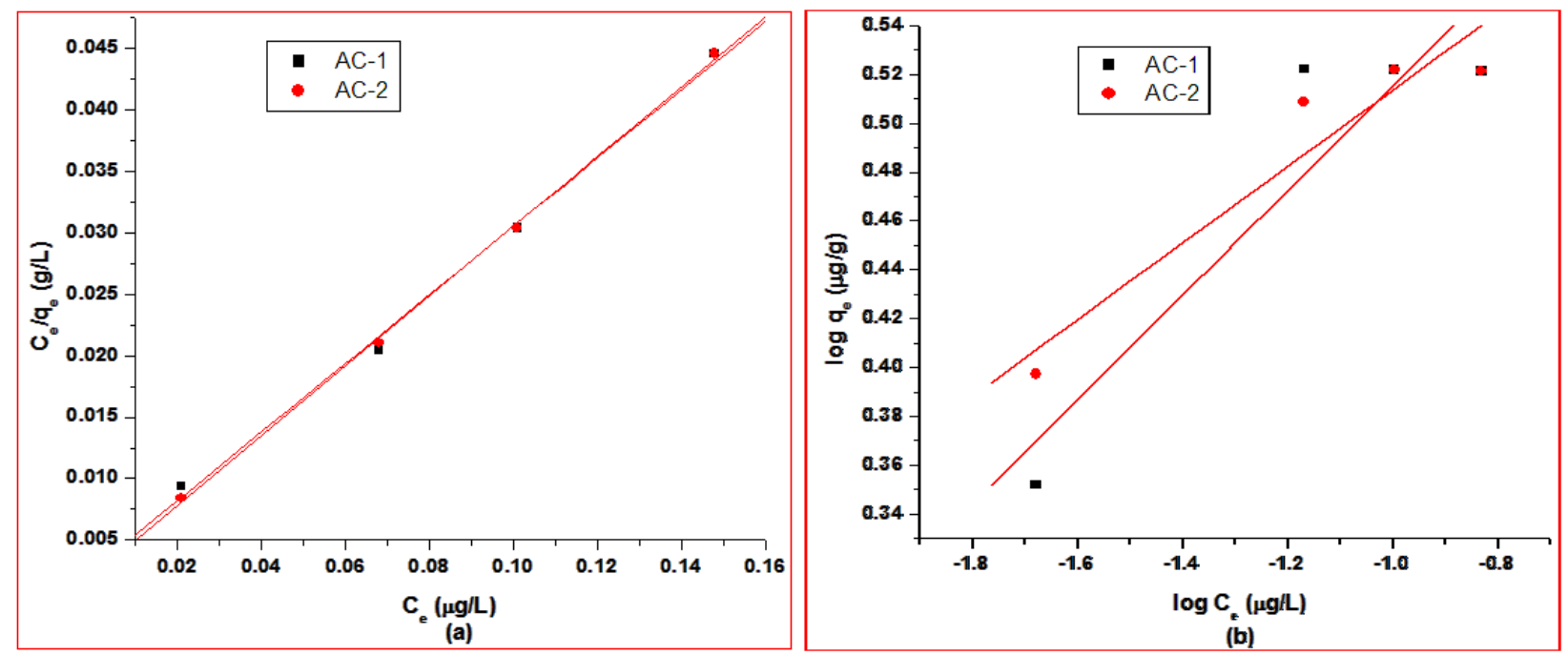

Figure 5: Adsorption of Phenol (a) Langmuir Isotherm Model (b) Freundlich Isotherm model

As it can be seen from Table 2, p values vary between 0.002 and 0.0004 ; looking at the variation of $\mathrm{p}$ values, it is seen that phenol adsorption mechanism with increasing temperature is more compatible with this model. The least $\mathrm{p}$-value is found for adsorption at $40^{\circ} \mathrm{C}$. A very low probability value demonstrates a very high significance for the regression model than the other model. Moreover, the values of NSD and ARE for both activated carbon is smaller in the Langmuir isotherm model than the Freundlich and Temkin models. Thus, these smaller values of NSD and ARE imply the experimental data is the best fit with Langmuir isotherm model.

Table 2: Isotherm Parameters for Phenolic compounds Adsorption on Activated Carbon.

\begin{tabular}{lrr}
\hline \multicolumn{1}{c}{$\begin{array}{c}\text { Adsorption isotherm } \\
\text { \& constants }\end{array}$} & \multicolumn{2}{c}{ Values } \\
\hline Langmuir & AC 1 & AC-2 \\
\hline $\mathrm{q}_{\mathrm{m}}(\mu \mathrm{g} / \mathrm{g})$ & 0.215 & 0.134 \\
$\mathrm{~b}_{\mathrm{L}}\left(\mathrm{L} \cdot \mu \mathrm{g}^{-1}\right)$ & -8.034 & -6.032 \\
$\mathrm{R}^{2}$ & 0.998 & 0.999 \\
$\mathrm{R}_{\mathrm{L} \cdot 10^{-5}(100 \mu \mathrm{g} / \mathrm{L})}$ & 9.4 & 16.8 \\
$\mathrm{NSD}$ & 0.018 & 0.023 \\
$\mathrm{ARE}$ & 0.325 & 1.004 \\
Probabilty & 0.002 & 0.0004 \\
Freundlich & & \\
$\mathrm{n}$ & 4.673 & 4.525 \\
$\mathrm{~K}_{\mathrm{f}}$ & 5.360 & 5.297 \\
$\mathrm{R}^{2}$ & 0.784 & 0.623 \\
NSD & 0.062 & 0.090 \\
ARE & 0.003 & 0.003 \\
Probability & 0.075 & 0.135
\end{tabular}




\begin{tabular}{lrr}
$\underline{\text { Temkin }}$ & & \\
\hline $\mathrm{b}_{\mathrm{T}}(\mathrm{kJ} / \mathrm{mol})$ & -37.577 & -36.655 \\
$\mathrm{a}_{\mathrm{T}}$ & 6.140 & 5.202 \\
$\mathrm{R}^{2}$ & 0.695 & 0.831 \\
$\mathrm{NSD}$ & 1.557 & 1.161 \\
$\mathrm{ARE}$ & 15.703 & 20.585 \\
Probability & 0.024 & 0.007 \\
\hline
\end{tabular}

\subsubsection{Freundlich Isotherm}

The Freundlich isotherm was originally empirical in nature but was later interpreted as sorption to heterogeneous surfaces or surfaces supporting sites of varied affinities. Assuming that stronger binding sites are occupied first and that the binding strength decreases with the increasing occupied site. Freundlich isotherm model is represented as:

$$
\log q_{e}=\log K_{F}+\frac{1}{n} \log C_{e}
$$

Where $\mathrm{q}_{\mathrm{e}}$ is the adsorption density $(\mu \mathrm{g} / \mathrm{g}), \mathrm{C}_{\mathrm{e}}$ is the concentration of the adsorbate in solution at equilibrium $\left(\mu \mathrm{g} / \mathrm{dm}^{3}\right) ; K_{F}$ and $1 / \mathrm{n}$ are the Freundlich constants. The plot of $\log \mathrm{q}_{\mathrm{e}}$ versus $\log \mathrm{C}_{\mathrm{e}}$ yields a straight line indicating to obey a Freundlich adsorption isotherm.

The numerical value of $1 / \mathrm{n}<1$ indicates that adsorption capacity is slightly suppressed at lower equilibrium concentrations. This isotherm does not predict any saturation of the sorbent by the sorbate; thus, mathematically infinite surface coverage is predicted, indicating multilayer adsorption on the surface. Freundlich adsorption isotherm gives an expression encompassing the surface heterogeneity and the exponential distribution of active sites and their energies indicate a multilayer sorption of the surface. A greater value of $\mathrm{K}_{\mathrm{F}}$ indicates a higher adsorption capacity. It can be stated that at $30^{\circ} \mathrm{C}$, adsorption capacity has the maximum value with 5.360 and $5.297 \mu \mathrm{g} / \mathrm{g}$ to $\mathrm{AC}-1$ and AC-2 on phenol adsorption respectively. The binding capacity and affinity between the adsorbent and phenol ions reach the highest value with high $\mathrm{K}_{\mathrm{F}}$ and $1 / \mathrm{n}$. Favorability of adsorption gives by the magnitude of the exponent $n$. It is generally stated that values of $n$ in the range of 2-10 represent good, 1-2 moderately difficultly, and less than 1 poor adsorption characteristics [34]. As can be seen from Table 2 and Figure 5(b), activated carbon is a good adsorbent for phenol adsorption $(4.525<\mathrm{n}<4.674)$. $\mathrm{P}$ values vary between 0.075 and 0.135 which is higher than the Langmuir isotherm model and this causes the value of $\mathrm{R}^{2}$ is smaller. Moreover, NSD and ARE values did not indicate the significance of the model for this isotherm, so the Freundlich isotherm is not the best isotherm model for the phenol adsorption mechanism.

\subsubsection{Temkin Isotherm}

Temkin isotherm derivation assumes that the fall in the heat of sorption is linear rather than logarithmic, as implied by the Freundlich equation. The heat of sorption of all molecules in the layer would decrease linearly with coverage due to sorbate/sorbent interactions. Temkin isotherm has generally been applied in the following form equation 9 [35]:

$$
q_{e}=\frac{2.303 R T}{b_{T}} \log a_{T}+\frac{2.303 R T}{b_{T}} \log C_{e}
$$

Where $b_{T}$ is the Temkin constant related to the heat of adsorption (Joules per mole), $a_{T}$ is the Temkin isotherm constant (liters per gram), $\mathrm{R}$ is the gas constant $(8.314 \mathrm{~J} / \mathrm{mol} \mathrm{K})$, and $\mathrm{T}$ is the absolute temperature $(\mathrm{K})$.

The parameters of Temkin model, as well as the correlation coefficients, are given in Table 2. The $\mathrm{R}^{2}$ values of activated carbons $(0.695$ and 0.831$)$ which are smaller than other isotherms and the higher values of NSD and ARE values of the model revealed that the experimental data didn't fit with the Temkin model. The variation of adsorption energy is negative ( -37.577 for AC-1 and $56.655 \mathrm{KJ} / \mathrm{mol}$ for $\mathrm{AC}-2$ at all the studied temperatures 303,308,313 K) respectively. From 
adsorption energy, one can conclude that the adsorption reaction is exothermic. In addition to this, the Temkin equilibrium binding constants for both ACs are 6.14 and $5.202 \mathrm{~L} / \mathrm{g}$ and the constant related to the heat of sorption $\left(B=R T / b_{T}\right)$ of $A C-1$ and $A C-2$ are -67.03 and $-44.46 \mathrm{~J} / \mathrm{mol}$. This value of the heat of sorption indicates the adsorption of phenolic compounds onto both ACs physisorption process. Generally, it is evaluated that $p$ values, NSD, and ARE values are in larger intervals for all two-parameter isotherm models. The two-parameter isotherm models are not more suitable for the phenol adsorption mechanism with increasing temperature.

\subsection{Adsorption Kinetics Model}

For any adsorption system, the study of chemical kinetics is very important so as to determine the rate constants for the reaction and to know how quickly or slowly the reaction is proceeding. Adsorption mechanism and characteristics used to explain by applying the kinetic model. Three kinetic models (pseudo-first order, pseudo-second order, and intra-particle diffusion, were applied to experimental data in order to investigate the kinetics of sorption of phenol on AC-1 and AC-2. Calculated kinetic parameters were depicted in Table 3.

\subsubsection{Pseudo First Order Reaction Kinetics}

The plots of $\log \left(\mathrm{q}_{\mathrm{e}}-\mathrm{q}_{\mathrm{t}}\right)$ versus $\mathrm{t}$ give a linear relationship, and $\mathrm{k}_{1}$ and qe values can be determined from the slope and the intercept of the equation.

$$
\log \left(q_{e}-q_{t}\right)=\log q_{e}-\frac{k_{1}}{2.303} t
$$

Where $\mathrm{q}_{\mathrm{e}}$ is the amount of phenol and phenolic compounds adsorbed at equilibrium $(\mu \mathrm{g} / \mathrm{g}), \mathrm{q}_{\mathrm{t}}$ is the amount of phenolic compounds adsorbed at time $t(\mu \mathrm{g} / \mathrm{g}), \mathrm{k}_{1}$ is the first order rate constant $\left(\mathrm{min}^{-1}\right)$ and $\mathrm{t}$ is a time in min. The rate constant $\left(\mathrm{k}_{1}\right)$ and equilibrium adsorption capacity $\left(\mathrm{q}_{\mathrm{e}}\right)$, can be calculated from the slope and intercept of straight line plot of $\log \left(\mathrm{q}_{\mathrm{e}}-\mathrm{q}_{\mathrm{t}}\right)$ against time $\mathrm{t}$.

Figure 6 (a) shows the linear plot of the pseudo-first-order equation and as can be seen, from table 3 the correlation coefficients obtained at $30^{\circ} \mathrm{C}$ for the pseudo-first-order kinetic model is 0.875 and 0.706 for AC-1 and AC-2 respectively. Thus, this study indicates that the kinetics of adsorption did not govern by pseudo-first order reaction. Also, the calculated $\mathrm{q}_{\mathrm{e}}(0.005,0.011)$ and the experimental $\mathrm{q}_{\mathrm{e}}(8.323,8.320)$ did not close to one another, this indicates that the pseudo-first order model was not fit for the adsorption of phenol by this locally prepared activated carbons.

\subsubsection{Pseudo Second Order}

The pseudo-second-order kinetic equation has been frequently employed to analyze sorption data obtained from various experiments [36,37].

$$
\frac{t}{q_{t}}=\frac{1}{h_{o}}+\frac{1}{q_{e}} t
$$

Where $\mathrm{q}_{\mathrm{t}}$ is the amount of phenolic compounds on the activated carbon surface $(\mu \mathrm{g} / \mathrm{g})$ at time $\mathrm{t}, \mathrm{q}_{\mathrm{e}}$ is the amount of phenolic compounds adsorbed at equilibrium, the initial sorption capacity $(\mu \mathrm{g} / \mathrm{min})$, $\mathrm{h}_{\mathrm{o}}$, is obtained as shown in equation (12).

$$
h_{o}=k_{2} q_{e}^{2}
$$

Where $\mathrm{k}_{2}$ is the Pseudo-second order rate constant (L/ $\mu$ g.min). $\mathrm{h}_{\mathrm{o}}$ and $\mathrm{k}_{2}$ are determined experimentally from the slope and intercept of a plot of $t / q_{t}$ against $t$. The $\mathrm{q}_{\mathrm{e}}$ and $\mathrm{k}_{2}$ values of the pseudo-second-order kinetic model can be determined from the slope and the intercept of the plots of $\mathrm{t} / \mathrm{q}$ versus $\mathrm{t}$, respectively. Figure 6 (b) gives the results of the linear form of the pseudo-secondorder kinetic model. The calculated qe $(3.328,3.327 \mu \mathrm{g} / \mathrm{g})$ values are same to the experimental data $(3.328,3.327)$ and the correlation factor as shown in table 3 is higher $\left(\mathrm{R}^{2}=1.00\right)$ than that of the pseudo-first order kinetics. Therefore, kinetics of the adsorption of phenol approximated more favorably by the pseudo-second-order model for both AC-1 and AC-2 [38]. 


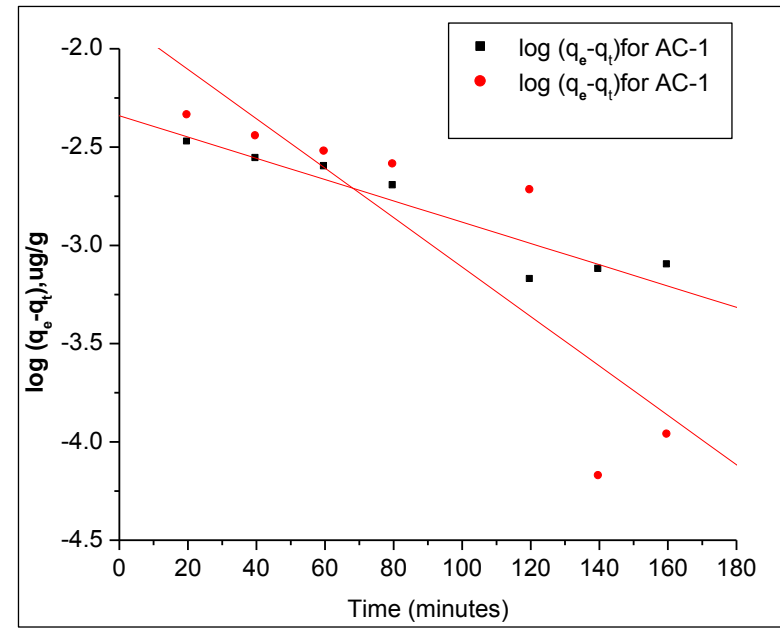

(a)

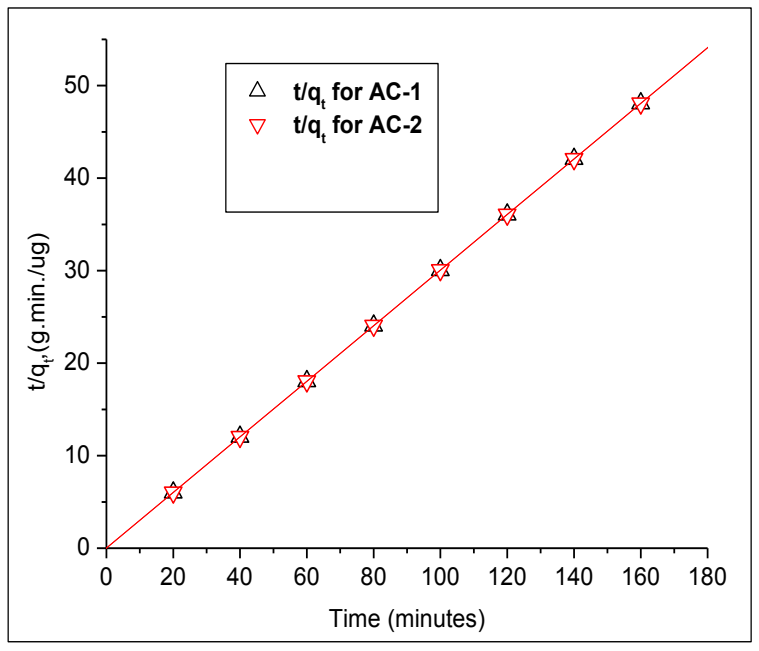

(b)

Figure 6: Kinetic model of AC-1 and AC-2; (a) Pseudo-first order and (b) Pseudo second order

\subsubsection{Intra-Particle Diffusion Model}

The adsorbate movement from the solution phase to the surface of the adsorbent particles occurs in several steps. Overall adsorption process may be controlled by one or more steps as film or surface diffusion, pore-diffusion, external diffusion, and adsorption on the pore surface or a combination of one or more than one step [39]. Intraparticle diffusion model or Weber-Morris equation is given by:

$$
q_{t}=k_{i d} t^{0.5}+C
$$

Where, $\mathrm{k}_{\mathrm{id}}$ is the intra-particle diffusion rate constant $\left(\mu \mathrm{g} / \mathrm{g} / \mathrm{min}^{1 / 2}\right), \mathrm{q}_{\mathrm{t}}(\mu \mathrm{g} / \mathrm{g})$ is a constant and $\mathrm{C}$ that gives an idea about the thickness of the boundary layer, i.e. the larger the value of $C$ the greater boundary layer effect. If the plot of $\mathrm{q}_{\mathrm{t}}$ versus $\mathrm{t}^{1 / 2}$ gives a straight line, then the sorption process was controlled by intraparticle diffusion only and slope gives the rate constant $\mathrm{k}_{\mathrm{id}}$. However, if the data exhibit multi-linear plots then two or more steps influenced the sorption process.

The plot of qt versus $\mathrm{t}^{0.5}$ for the adsorption of phenol onto AC- 1 and AC-2 at different temperatures was found to be not fitting the data since line did not pass the origin. The plot also indicates that the pore diffusion is the only rate-limiting step. Calculated $\mathrm{C}$ values found to be decreased with increasing temperature indicating that the boundary layer effect is higher in low temperatures for the adsorption of phenol onto both activated carbons. The correlation coefficients and the kinetic parameters are given in Table 3 are representing that the intra-particle diffusion model shows a lower representation of the data than the pseudo-first-order kinetic model. The result of intraparticle diffusion rate constant $\mathrm{k}_{\mathrm{id}}$ was observed to be higher at a higher temperature suggesting consistency with the fact that the diffusion needs some energy to overcome the mass transfer resistance [39].

Table 3: Kinetics Parameters for the Adsorption of Phenol on Activated Carbon Prepared from Avocado Kernel Seeds

\begin{tabular}{ccc}
\hline $\begin{array}{c}\text { Kinetic model } \& \\
\text { constants }\end{array}$ & \multicolumn{2}{c}{ Values } \\
\hline $\mathrm{q}_{\mathrm{e}}$ (exp) & 3.328 & AC-2 \\
\hline $\begin{array}{c}\text { Pseudo-first order } \\
\mathrm{q}_{\mathrm{e}} \text { (cal) }\end{array}$ & 0.005 & 0.011 \\
$\mathrm{k}_{1}$ & 0.012 & 0.023 \\
$\mathrm{R}^{2}$ & 0.875 & 0.706 \\
Pseudo-second order & & \\
$\mathrm{q}_{\mathrm{e}}$ (cal) & 3.328 & 3.328 \\
$\mathrm{k}_{2}$ & 9.91 & 5.055 \\
$\mathrm{R}^{2}$ & 1.000 & 1.000
\end{tabular}




\section{Intraparticle Diffusion}

\begin{tabular}{ccc}
$\mathrm{K}_{\mathrm{id}}$ & 1.112 & 1.112 \\
$\mathrm{C}$ & -5.105 & -5.103 \\
$\mathrm{R}^{2}$ & 0.872 & 0.872 \\
\hline
\end{tabular}

\subsection{Thermodynamic Studies}

The adsorption equilibrium constant $\mathrm{K}_{\mathrm{o}}$ was estimated from the expression of equation 14 .

$$
K_{o}=\frac{C_{o}}{C_{e}}
$$

The thermodynamic parameters were determined according to equations (15 and 16) as given below

$$
\begin{aligned}
& \Delta G^{O}=-R T \ln K_{o} \\
& \ln K_{o}=\frac{\Delta S^{O}}{R}-\frac{\Delta \mathrm{H}^{O}}{R T}
\end{aligned}
$$

The values of $\Delta \mathrm{H}^{\mathrm{O}}$ and $\Delta \mathrm{S}^{\mathrm{O}}$ were calculated from the slope and intercept of the linear plot of $\ln \mathrm{K}_{\mathrm{o}}$ against reciprocal of temperature $(1 / \mathrm{T})$. Using the $\mathrm{K}$ values determined from the adsorption isotherm equations (14-16), the corresponding values of $\Delta \mathrm{G}$ of adsorption determined at different experimental temperatures. The values of $\Delta \mathrm{H}$ and $\Delta \mathrm{S}$ can be determined from the slope and the intercept of the linear plot of $\ln \mathrm{K}_{\mathrm{o}}$ versus $1 / \mathrm{T}$. The equilibrium constants obtained from the initial concentration of phenol at 303,308 , and $313 \mathrm{~K}$ were used to determine the Gibbs free energy.

The van't Hoff plot for the adsorption of the phenol onto both AC -1 and AC-2 is given in the relation of $\ln \mathrm{K}_{\mathrm{o}}$ versus 1/T. The thermodynamic parameters obtained were summarized in Table 4. The exothermic nature of the process for both AC- 1 and $\mathrm{AC}-2$ is well explained by the negative value of the enthalpy change (Table 4). Moreover, it was observed that all the values of the enthalpy are fallen between -40 to $-400 \mathrm{KJ} / \mathrm{mol}(-69.36,-146.011$, and $-212.40 \mathrm{KJ} / \mathrm{mol})$; consequently, the process of adsorption of phenol on both activated carbons are chemical, and chemisorptions take place on the enthalpy values. The negative values of $\Delta S$ correspond to a decrease in the degree of freedom of the adsorbed species, suggesting strong interactions between phenol and activated carbons [40].

Negative $\Delta \mathrm{G}^{\circ}$ values were observed for all temperatures and concentrations $\left(\begin{array}{lll}10 & -30 \mu \mathrm{g} / \mathrm{L}\end{array}\right)$, indicating that spontaneity of the adsorption process is favored for the phenol/activated carbon system. $\Delta \mathrm{H}^{\mathrm{o}}$ derived for the initial concentration of phenol with $\mathrm{AC}-1$ and $\mathrm{AC}-2$ was larger than $40 \mathrm{~kJ} / \mathrm{mol}$, which is comparable to those reported for adsorption of phenol on non-ionic polymeric resins [41, 42]. Therefore, it seems that phenol adsorption by AC would be attributed to a type of chemical adsorption rather than a purely physical or chemical adsorption process.

Table 4: Thermodynamic Parameters for the Adsorption of Phenol onto Avocado Kernel Seed Activated Carbon at $\mathrm{pH} 6$

\begin{tabular}{ccccccc}
\hline \multicolumn{2}{c}{$\begin{array}{c}\text { Concentration } \\
(\boldsymbol{\mu} \mathbf{g} / \mathbf{L})\end{array}$} & Temp.(K) & $\begin{array}{c}\ln \mathbf{K}_{\mathbf{0}}= \\
\mathbf{l n}_{\mathbf{0}} \mathbf{C}_{\mathbf{0}} / \mathbf{C}_{\mathbf{e}}\end{array}$ & $\begin{array}{c}\Delta_{\text {ads }} \mathbf{G} \\
(\mathbf{k J J} / \mathbf{m o l})\end{array}$ & $\begin{array}{c}\Delta_{\text {ads }} \mathbf{H} \\
(\mathbf{k J} / \mathbf{m o l})\end{array}$ & $\begin{array}{c}\Delta_{\text {ads }} \mathbf{S} \\
(\mathbf{J} / \mathbf{K . m o l})\end{array}$ \\
\hline \multirow{3}{*}{10} & 0.033 & 303.000 & 5.723 & -14.417 & & \\
& 0.046 & 308.000 & 5.382 & -13.781 & -69.360 & -181.040 \\
& 0.079 & 313.000 & 4.842 & -12.600 & & \\
\hline \multirow{2}{*}{20} & 0.093 & 303.000 & 5.371 & -13.512 & & \\
& 0.018 & 308.000 & 6.997 & -17.916 & -146.011 & -430.200 \\
& 0.609 & 313.000 & 3.491 & -9.085 & & \\
\hline \multirow{2}{*}{30} & 0.043 & 303.000 & 6.541 & -16.477 & & \\
& 0.143 & 308.000 & 5.348 & -13.695 & -212.400 & -648.800 \\
& 0.648 & 313.000 & 3.835 & -9.979 & & \\
\hline
\end{tabular}




\section{CONCLUSION}

Phenolic compounds can be removed effectively from Avocado kernel seed generated activated carbon. Batch adsorption was applied and the result revealed that the equilibrium adsorption attained at 100 and 120 minutes for AC- 1 and AC-2 respectively. The adsorption isotherm can be well described with Langmuir model within the studied conditions. Results of kinetics study indicate that the pseudo-second-order kinetics can simulate the adsorption process with a high accuracy for the adsorption of phenolic compounds both from drinking water and aqueous solution. Thermodynamic parameters for adsorption such as $\Delta \mathrm{H}, \Delta \mathrm{S}$ and $\Delta \mathrm{G}$ were calculated for adsorption process and the result showed that the free energy, enthalpy and entropy of adsorption were -13.6 $\mathrm{kJ} / \mathrm{mol},-69.36 \mathrm{~kJ} / \mathrm{mol}$ and $-181.04 \mathrm{~J} / \mathrm{K}$ at $30^{\circ} \mathrm{C}$. It indicates that the adsorption of phenol is spontaneous, chemisorbed, mono-layered and exothermic on activated carbon prepared from avocado kernel seeds.

\section{ACKNOWLEDGMENT}

We thankfully acknowledge to the Department of Chemistry, College of Natural Science, Jimma University, Ethiopia for providing all necessary facilities required for carrying out this work.

\section{REFERENCES}

[1] G. B. Busca, C. Resini, L. Arrighi, Technologies for the removal of phenol from fluid streams: a short review of recent developments, J. Hazard. Mater, 160 (2008) 265-288.

[2] I. Ali, M. Asim, T. A. Khan, Low cost adsorbents for the removal of organic pollutants from wastewater, J. Environ. Manage. 113 (2012) 170-183.

[3] I. Ali, H. Y. Aboul-Enein, "Chiral, Pollutants: Distribution, Toxicity, and Analysis by Chromatography and Capillary Electrophoresis". John Wiley \& Sons, 2004.

[4] B. Damià, "Emerging Organic Pollutants in Waste Waters and Sludge", $5^{\text {th }}$ Ed, Springer, Berlin, 2005.

[5] H. F. Herbert, C. On-chim, Toxicity of phenol towards aerobic biogranules, Water Res., 31 (1997) 2229-2242.

[6] F. A. Banat, B. Al-Bashir, S. Al-Asheh, O. Hayajneh, Adsorption of phenol by bentonite, Environ. Pollut. 107 (2000) 391-398.

[7] B. Ozkaya, Adsorption and desorption of phenol on activated carbon and a comparison of isotherm models, J. Hazard. Mater. B129 (2006) 158-163.

[8] G. G. Stavropoulos, P. Samaras, G. P. Sakellaropoulos, Effect of activated carbons modification on porosity, surface structure and phenol adsorption, J. Hazard. Mater, 151 (2008) 414-421.

[9] I. I. Salame, T. J. Bandosz, Role of surface chemistry in adsorption of phenol on activated carbons, J Colloid Interf. Sci., 264 (2003) 307-312.

[10] S. P. Kamble, P. A. Mangrulkar, A. K. Bansiwal, S. S. Rayalu, Adsorption of phenol and ochlorophenol on surface altered fly ash based molecular sieves, Chem. Eng. J., 138 (2008) $73-$ 83.

[11] S. Asheh, F. Banat, A. Aitah, Adsorption of phenol using different types of activated bentonites, Sep. Purif. Technol. 33 (2003) 1-10.

[12] H. S. Gopalkrishnamoorthy, T. Shanmugam, Study of the removal of phenol from effluent of low temperature carbonization of lignite plant by resins, Indian J. Environ. Protection, 7 (1987) 352-354.

[13] K. H. Choy, J. F. Porter, G. McKay, Langmuir, isotherms models applied to the multicomponent sorption of acid dyes from effluent onto activated carbon, J. Chem. Eng. Data, 45 (2000) 575-584.

[14] C. Namasivayam, N. Muniasamy, K. Gayatri, M. Rani, K. Ranganathan, Removal of dyes from aqueous solutions by cellulosic waste orange peel, Bioresource Technol. 57 (1996) 37-43. 
[15] E. Forgacs, T. Cserháti, G. Oros, Removal of synthetic dyes from wastewaters: A review, Environ Int. 30 (2004) 953-971.

[16] J. Sarma, A. Sarma, K. G. Bhattacharyya, Biosorption of commercial dyes on Azadiracta indica leaf powder: A case study with a basic dye Rhodamine B. Ind. Eng. Chem. Res, 47 (2008) 5433-5440.

[17] R. P. Han, Y. F. Wnag, P. Han, J. Yang, Y. S. Lu, Removal of methylene blue from aqueous solution by chaff in batch mode, J. Hazard. Mater. 137 (2006) 550-557.

[18] Z. Aksu, Application of biosorption for the removal of organic pollutants: a review, Process Biochem. 40 (2005) 997-1026.

[19] C. Gregorio, Recent developments in polysaccharide-based materials used as adsorbents in wastewater treatment, Prog. Polym. Sci. 30 (2005), 38-70.

[20] B. Adane, K. Siraj and N. Meka, Kinetic, equilibrium and thermodynamic study of 2chlorophenol adsorption onto Ricinus communis pericarp activated carbon from aqueous solutions, Green Chemistry Letters and Reviews, 8 (2015) 1-12.

[21] Mariia P. Elizalde-Gonza'lez, J. Mattusch, Alejandra A. Pela'ez-Cid, R. Wennrich, Characterization of adsorbent materials prepared from avocado kernel seeds: Natural, activated and carbonized forms, J. Anal. Appl. Pyrolysis, 78 (2007) 185-193

[22] L. Khenniche, F. Aissani, Preparation and Characterization of Carbons from Coffee Residue: Adsorption of Salicylic Acid on the Prepared Carbons, J. Chem. Eng. Data, 55 (2010) 728-734.

[23] A. L. Ahmad, M. M. Joh, J. A. Aziz, Preparation and characterization of activated carbon from oil palm wood and its evaluation on Methylene blue adsorption Dyes, Dyes and Pigment, 75 (2007) 263-272.

[24] M. S. Pakuła, M. Walczyk, S. Biniak, Voltammetric and FT-IR studies of modified activated carbon systems with phenol, 4-chlorophenol or 1,4-benzoquinone adsorbed from aqueous electrolyte solutions, Colloid Surface, 260 (2005) 145-155.

[25] M. Sathishkumar, A. R. Binupriya, K. Vijayaraghavan, S. Yun, Two and three-parameter isothermal modeling for liquid-phase sorption of Procion Blue $\mathrm{H}-\mathrm{B}$ by inactive mycelialbiomass of Panus fulvus, J. Chem. Technol. Biot. 82 (2007) 389-398.

[26] B. F. Noeline, D. M. Manohar, T. S. Anirudhan, Kinetic and equilibrium modelling of lead (II) sorption from water and wastewater by polymerized banana stem in a batch reactor, Sep. Purif. Technol. 45 (2005) 131-140.

[27] I.I. Salame, T. J. Bandosz, Role of surface chemistry in adsorption of phenol on activated carbons, J. Colloid Interf. Sci. 264 (2003) 307-312.

[28] P. Podkoscielny, K. Nieszporek, Heterogeneity of activated carbons in adsorption of phenols from aqueous solutions-Comparison of experimental isotherm data and simulation predictions, Applied Surface Science, 253 (2007) 3563-3570.

[29] M. Dai, Mechanism of adsorption for Dyes on activated carbon, J. Colloid Interf. Sci. 198 (1998) 6-10.

[30] K.P. Singh, S. Sinha, P. Ojha, Liquid-phase adsorption of phenols using activated carbons derived from agricultural waste material, J. Hazard. Mater. 150 (2008) 626-641.

[31] A. Behnamfard, M.M. Salarirad, Equilibrium and kinetic studies on free cyanide adsorption from aqueous solution by activated carbon, J. Hazard. Mater, 170 (2009) 127-133.

[32] G. Ghanizadeh, G. Asgari, Adsorption kinetics of methylene blue and its removal from aqueous by bone charcoal, Reac. Kinet. Mech. Cat. 102 (2011) 127-142.

[33] K.R. Hall, L.C. Eagleton, A. Acrivos, T. Vermeulen, Pore and solid diffusion kinetics in fixedbed adsorption under constant pattern conditions, Ind. Eng. Chem. Fund., 5 (1966) 212-223.

[34] R.E. Treybal, "Mass transfer operations". $3^{\text {rd }}$ Edition, McGraw-Hill: New York, 1980.

[35] M.I. Temkin, Adsorption equilibrium and the kinetics of processes on nonhomogeneous surfaces and in the interaction between adsorbed molecules, Zhurnal Fiziche- skoi Khimii, 15 (1941) 296-332.

[36] G. Blanchard, M. Maunaye, G. Martin, Removal of heavy metals from waters by means of natural zeolites, Water Res., 18 (1984) 1501-1507. 
[37] Y.S. Ho, J.C.Y. Ng, G. McKay, Kinetics of pollution sorption by biosorbents review, Sep. Purif. Method, 29 (2000) 189-232.

[38] B.H. Hameed, L.H. Chin, S. Rengaraj, Adsorption of 4-chlorophenol onto activated carbon prepared from rattan sawdust, Desalination, 225 (2008) 185-198.

[39] J. Wu, H.K. Yu, Biosorption of 2, 4 dichlorophenol from aqueous solution Phanerochaete chrysosporium biomass: Isotherms, kinetics and thermodynamics, J. Hazard. Mater. B137 (2006) 498-508.

[40] Q. Fu, Y. Deng, H. Li, J. Liu, H. Hu, S. Chen, T. Sa, Equilibrium, kinetic and thermodynamic studies on the adsorption of the toxins of Bacillus thuringiensis subsp. kurstaki by clay minerals, Applied Surface Science, 255 (2009) 4551-4557.

[41] R.S. Juang, J.Y. Shiau, Adsorption isotherms of phenols from water onto macroreticular resins, J. Hazard. Mater. B70 (1999) 171-183.

[42] K.Y. Foo, B.H. Hameed, Insights into the modeling of adsorption isotherm systems, Chem. Eng. J. 156 (2010) 2-10. 